\title{
Eğitim Açısından Felsefe ve Sanat ilişkisi
}

\author{
Doç. Dr. Fulya Bayraktar
}

\section{Öz}

Bu çalışmada, felsefe eğitimi için sanatın, sanat eğitimi için felsefenin taşıdığı anlam üzerinde durulacak, bu karşılıklı ilişkide sanatlı bir felsefe eğitiminin ve felsefeli bir sanat eğitiminin imkânları ve ufukları değerlendirilecektir. Örnekler üzerinden, sanatın felsefede, felsefenin sanatta yaratacağı derinlik irdelenecektir. Derinlikli bir sanat için felsefi kültür ve tutum yol gösterici olurken, kuşatıcı ve kavramlarda derinleşme imkânı veren bir felsefe için de sanat, ufuk açıı bir mahiyet taşır. Sanatı anlamlı kılan bir temel etkinlik olarak felsefeyle bütünleşebilen bir sanat için, felsefeyle yoğrulmuş bir sanat eğitimine ihtiyaç vardır. Aynı şekilde, somutlaştırılamayan bir tefekkür alanının, somut algısına imkân veren bir etkinlik olarak sanatla bütünleşebilen bir felsefe eğitimine ihtiyaç vardır.

Anahtar Kelimeler: Felsefe, Sanat, Eğitim, Felsefe Eğitimi, Sanat Eğitimi

\section{ART IN THE EDUCATION PHILOSOPHY, PHILOSOPHY IN THE EDUCATION ART}

\begin{abstract}
In this research, the meaning of art for philosophical education and the meaning of philosophy for artistic education will be investigated and in this reciprocal relation, the cornerstones of an art-based philosophy education and a philosophy-based art education will be argued. While the philosophical attitude and culture have a leading role for detailed art, the art opens a new horizon for a philosophy, which makes it possible to have a deepening insight into comprehensive concepts. The deepness of the impact of art on philosophy and the impact of philosophy on art will be discussed through examples. For art to identify with philosophy, it is necessary to have an arts education combined with philosophy. Because, philosophy is an activity that makes art meaningful. In the same way it is necessary to have a philosophical education that can identify with art. The reason is that art is an activity that renders a concrete perception of a domain of reflection that cannot be made concrete.
\end{abstract}

Keywords: Philosophy, Art, Education, Philosophical Education, Artistic Education 
Insanoğlunun kendisini ve evreni anlamak, anlamlandırmak için ortaya koyduğu iki temel faaliyet alanıdır felsefe ve sanat. Birlikte düşünüldüklerinde, biri diğerini besleyen, birbirine ufuk açan iki disiplindir. Felsefe alanında varlığı, bilgiyi, değerleri araştıııken; sanat alanında estetik bir boyut yakalamaya çalışır insan. İnsanın kendini anlamlandırma çabasının vazgeçilmez iki etkinliği olan felsefe ve sanat, çoğu zaman birbirlerini, kendilerini anlatmak için farklı bir ifade alanı, başka bir dil imkânı olarak kullanırlar. Fakat aynı zamanda kendi alanlarında derinleşebilmek için de birbirlerine intiyaç duyarlar. Derinlikli bir sanat için felsefi kültür ve tutum yol gösterici olurken, kuşatıcı ve kavramlarda derinleşme imkânı veren bir felsefe için de sanat, ufuk açıcı bir mahiyet taşır.

Felsefe eğer bütünlüklü bir evren ve insan tasavvuruna ulaşmak istiyorsa, etik ve estetik ihtiyaçları ve hedefleri olan bir değer varlığı olarak insanı göz ardı edemez. Bu bakımdan sanatı, sanatın doğasını, sanatsal yaratıyı ve onu ortaya koyan insan şahsiyetini anlama çabası felsefi bir faaliyet alanı olarak düşünülür. Fakat bu iki disiplin arasında asıl olan ve felsefenin sanatı kendine konu edinmesinden daha temel bir ilişki kurulabilir. Sanat eserleri yoluyla felsefeyi anlatmak, bu ilişkinin hareket noktası olarak düşünülebilir. Bu noktada sanatın, aynı zamanda felsefe eğitimi için bir materyal olarak değerlendirilmesi gerekmektedir. Felsefe problemlerinin somutlaşması, insanlık durumları üzerinden kavranabilmesi için bir imkân alanıdır sanat. Sanat, subjektif bir dildir, fakat intersubjektif bir anlam alanı oluşturur. Subjektif dil içerisinde evrensel bir iletişim imkânı verir. Sanat, insanı bir kavram olmaktan çıkarır. Diğer taraftan felsefe de, sanatın bu subjektif dili için evrensel bir anlatım imkânı verir. Felsefe, sanat eserlerini yalnızca birer nesne olmaktan kurtarır. Bu bağlamda, felsefeyi sanatla, sanatı felsefe ile beraber değerlendirmek, hatta bu alanların eğitimini birbirinden beslenecek şekilde düşünmek gerekmektedir. Zira evreni, insanı ve değerleri anlama ve anlamlandırma çabası, felsefi olmakla beraber, sadece filozofları ilgilendiren ya da ilgilendirmesi gereken bir çaba değildir. En az felsefe kadar, sanatın da bu sorgulamaya intiyacı vardır. Sanatı anlamlı kılan bir temel etkinlik olarak felsefeyle bütünleşebilen bir sanat için, felsefeyle yoğrulmuş bir sanat eğitimine intiyaç vardır. Aynı şekilde, somutlaştırılamayan bir tefekkür alanının, somut algısına imkân veren bir etkinlik olarak sanatla bütünleşebilen bir felsefe eğitimine intiyaç vardır.

Bu nedenle, felsefe eğitimi için sanatın, sanat eğitimi için felsefenin taşıdığı anlam üzerinde durulmalı, bu karşılıkıı ilişkide sanatı bir felsefe 
eğitiminin ve felsefeli bir sanat eğitiminin imkânları ve ufukları değerlendirilmeli, sanatın felsefede, felsefenin sanatta yaratacağı derinlik irdelenmelidir.

Düşünceyle bağı kopmuş bir sanat olamayacağı gibi, sanata bigâne bir düşünce de tamamlanmış olmayacaktır. Sanatın, tarihi boyunca düşünce ile olan ilişkisi göz önünde bulundurulduğunda, pek çok sanat eseri doğrudan bir felsefenin ifadesi olarak değerlendirilebilir. Bu bağlamda felsefeye ilişkin olarak verilecek bir eğitimde sanat eserleri zaten kendi manifestasyonları dolayısıyla işaret etmekte oldukları felsefeler için bir anlatım imkânı olurlar. Ancak bununla da sınırlı kalmazlar zira sanat eserleri yorumlanabilirlikleri dolayısı ile de yorumlamadaki bağlamlarınıza bağlı olarak istediğiniz felsefi problematiğin aktarımında vesile olabilirler.

Sanatın özünde temsil vardır. $\mathrm{O}$, gerçeğin vekilidir. Bu nedenle de yoruma açıktır sanat eseri. Bu bağlamda felsefeci, sanat eserini, anlatmak istediği hakikat için uygun bir yorumla kullanma imkânına sahiptir. Umberto Eco, müzik, resim ve heykeli açık yapıt olarak tanımlar ve bunların yoruma açık olduklarını söyler. Sanat eserini alımlayanın en az sanatçısı kadar yorum hakkı vardır eser üzerinde. Postmodern yaklaşım bunu daha da güçlendirmiştir. Yapıbozumcular da aynı şekilde, yorumcu ile sanatçı arasında öncelik hakkı bulunmadığını ifade eder. Her yorum aynı derecede geçerlidir.

Bir sanat eserini yorumlarken sadece anlatmak istediğimiz bir fikrin göstereni olarak o eseri kullanmayız, aynı zamanda o yorumlama esnasında fikri bir derinleşme kazanırız ve bir eseri yorumlama çabasında kendimizi de yorumlarız. Yorum, önyargılarımız ve kişisel birikimlerimizden sıyrılmış olamaz. Kendi ruhumuzu tanımadan yüksek sanat eserlerini yorumlayamayız. Bu bağlamda aslında sanat eseri yaratmak kadar sanat eseri yorumlamak da bir tür arınma gerektirir. Bu nedenle de sanat eserleri hem yaratıcısı için hem de yorumlayıcısı için hakikatle karşılaşma aracıdır.

Kısaca sanat eserleri, hem sanatçının ifade etmek istediği fikir bağlamında, hem de yorumlayıııın ona yüklediği anlam bağlamında bir fikrin somut algısını oluşturmak için aracı olurlar. Ayrıca bu yorumlama esnasında yorumcuya derinlik kazandırırlar. Elbette bu, sanatın felsefe için bir araç olarak kullanılmaya indirgenmesi anlamında düşünülmemelidir zira zaten gerçek sanat, düşünceden ve felsefeden bağımsız değildir. Bu sadece sanatı, bütün diğer amaçlarının yanında, felsefe eğitimi için de materyal, konu, etkinlik olarak düşünme teklifidir. Ancak sanat eseri, hakikate işaret eden bir sembol olarak 
değerlendirilmelidir. Çünkü teşhir etmek hakikati kavramak için yabancılaşmak anlamına da gelebileceğinden, buradaki ince ayırımı gözden kaçırmamak gerekir. Özü gereği hakikat ehli tarafından fark edilebileceği için, gerçek sanat da o hakikati işaret eden ellerden biri olmakla beraber, eli değil, işaret ettiği yeri görmektir esas olan. Göstereni, gösterilenin yerine geçirmeden sanatı kullanmak gerekir. Mesela geleneksel sanatlarımız, görsel olanları dahi açık açık gösteren değil, ima eden, sezdiren sanatlardı. Bunların bu ifade biçimleri bile hakikate ilişkin bir anlatım imkânı verebilir felsefeye.

Görsellik çağı da diyebileceğimiz bir çağda, algının en çok da görsel algıya indirgendiği bir çağda, görselliği de kullanmadan bir düşünceyi anlatmaya çalışmak çok güçtür. Zira görme, en dolayımsız algıdır. Ve bu nedenle de, bırakınız algıya değil de anlamaya hitabeden bir yöntemi, diğer duyulara hitabeden uyaranlardan da daha güçlü bir anlatım imkânı verir görsel olanlar. Mesela, masal dinlemek hayal gücünü geliştirir. Bir masalı görsel olarak izlemek ise hayal imkânlarını sınırlandırır. Dolayısıyla esasen masalın kendisi, sanat olarak belki daha yüksek bir seviyedir ve onu filme dönüştürenin düşünsel altyapısıdır ancak bir masalı anlatmaktan daha etkili olabilir o masalın filmini izlemek. Bu bağlamda, görsellikle işitselliği buluşturan bir modern sanat olarak sinema, felsefe eğitimi için bir materyal olarak düşünülebilir. Bu, felsefeyi de basite indirgemeden, duyulur düzleme taşıma imkânı verir. Dinlemeyi öğrenmek de, görmeyi öğrenmek de zaman alır. Fakat düşünmeyi öğrenmeye giden yolun taşlarıdır bunlar. Ya da diyalektik bir biçimde, düşünme bunların yolunu açar.

Sanat eğitiminde de felsefe yalnızca düşünsel bir temel olmakla kalmaz, aynı zamanda sanatın anlatım imkânlarını da genişletir. Mesela, sadece göze ve görselliğe hitabeden bol ödüllü filmler vardır. Görsellikteki anlatım gücü dolayısıyla takdir görmüş ancak hikâyesi ve dili olmayan filmlerdir. Edebiyatın, hikâyenin, anlatımın, hatta düşünsel arka planın zayıflığı görsellikteki maharetle kapatılmıştır. Bunları birbirinin yerine koymaktansa, birlikte konumlandırmak büyük zenginlik olurdu.

İşitme, duyma, dinleme yetisi, hayâli destekleyen çağrışımları daha güçlü ve hakikati imâ etmekte daha etkilidir. Masal, destan, halk hikâyeleri, Karagöz, seyirlik oyunlar gibi etkisi yüksek sanatlar, tamamen söze dayalıdır ve aslında sanki hat, tezhib, ebru gibi sanatlarımız da görmeye hitabediyormuş gibi algılansa da esasen duymaya, görünür olanı dinlemeye hitabederler. Çünkü görme yetisi kötüye kullanıldığında, suretin mânâ yerine geçme tehlikesi her zaman vardır. Fakat esasında 
göze hitabetmek de kulağa hitabetmek de kavramlarla anlatmaya nazaran eşit derecede sanatın maharetidir. İster duymaya ister görmeye hitabetsin, sanatın anlatım gücü tartışımaz. Söz sanatları da, hakikate işaret etmek için kullanılan sanatsal aracılardır. Görme, işitmeden daha etkili ve önceliklidir. İsitme, görmeden daha derinlikli ve hayal gücünü zorlayıcıdır. Belki de bu nedenle, işaret ettiğimiz hakikate göre bu sanatlardan her birini ayrı ayrı kullanabiliriz. Doğu'nun şiire ve musıkîye taşıtmakta olduğu mânâlar, Batı'nın tasvire ve tersime yüklediği değer, düşüncenin tarihi ile sanatın tarihini bu nedenle ayrılmaz hâle getirir. Bu beraberlikten, bugün yeni bir anlam çıkarmalı ve şimdi biz, göze de kulağa da hitabedebilen, hayal gücüyle buluşan, tefekkür için ufuk açabilen anlatım imkânları bulmalıyız.

Kelime ve hayâlin soyutluğundan, şekil ve suretin somutluğuna, şekil ve suretin somut ifadesi üzerinden arkasındaki kelâmın mânasına geçiş sağlayan bir felsefe ve sanat birlikteliği hiç de zor değildir. Sanatın aynasında felsefeyi temaşa etmek, felsefeye de sanata da ufuk açacaktır.

Hakikatin kelamla, şiirle, edebiyatla ifadesi; duyarak, dinleyerek daha derin bir etki uyandırırken, müzikle ifadesi sonsuz bir hakikat tasavvuru imkânıdır. Tasvirle, tersimle ifadesi ise üzerinden düşünerek arkasındaki anlama ulaşabilmek için bir vesile olarak değerlendirilebilir. Metafizik-ontolojik bir meselenin en iyi anlatım yoludur sanat. "Bir küçük örnek olarak, "BibliaPauperum" verilebilir. Yani yoksulların Kitabı Mukaddesi, okuma yazması olmayanların. VI. Yüzyılda Papa Gregorius Magnus, "harfler okuma yazma bilenler için ne ise, resimler de okuma yazma bilmeyenler için aynı şeydir" der. Böylelikle Kitab-ı Mukaddes kıssaları resmedilmeye başlar (Cündioğlu, 2013: 151). Hakikate ilişkin olarak söylemek istediklerini, resimle söylerler. Çok geniş bir kitleye, çok etkili bir şekilde ulaştığı âşikârdır. Hatta metinlerde var olmayan ancak sanatçının kendi hayal gücünün ürünü olan tasvirlerin bugün bile hakikat algısında etkisi büyüktür. "Yahudi ve Müslüman bilinci ise görsellikte bir teşhir yönü görmüş ayrıca görünenin arkasındaki mânâyı perdeleyeceğini düşünmüş ve bu nedenle de daha dolayımlı olanı tercih etmiştir. İşitselliği. Görerek bilmek yerine duyarak bilmeyi" (Cündioğlu, 2013: 152). Edebiyatın her türündeki büyük eserler bunun örneğidir. Mesnevîler, dîvanlar v.s. ... Mesela, Mevlânâ; "renksizlik renge esir olunca, bir Musa öbür Musa ile savaşa düştü" diyor. "Renksizlik âlemine ulaşırsan, Mûsa ile Firavun'un birbiriyle sulhta olduğu âleme erişirsin" (Mesnevî, I/b, 2467-68). Sulh renksizlik âleminde gerçekleşmektedir. Belki de bu fikri anlatmak için, renk kullanmaz hattatlar. Hat sanatının üslubu bile arkasındaki bir ontolojiye işaret etmektedir. Mesela 
minyatürlerdeki gece tasvirlerine bakalım. Gece ile gündüz arasında hiçbir fark yoktur, birkaç yıldız ve hilalden başka. Bu, minyatürün arkasındaki evren algısı ile ilgilidir. Ayrıntılarına girmeden bir cümle ile söyleyecek olursak; Hakk'tan olan herşey birbiri ile eşit derecededir. Her mevsim bahar, her dem gündüzdür görene. Bu tasvirler hakikatin anlatımlarıdır. Zira bütün evren hakikatin yansımasıdır. Değil mi ki;

\section{Âdeme eşyada esmâ görünür \\ Cümle esmadan müsemmâ görünür. (Niyazi-i Mısrî)}

Esasen, gelenekte, değerlerin temsilcisi olan “Hoca"ların oynadığı rolü, yani görünür hâle getirme rolünü, şimdi acaba sanata da yükleyebilir miyiz, diye düşünüyoruz. Felsefe eğitimi de sanat eğitimi de kendi geleneğinde usta-çırak, hoca-öğrenci ilişkisi içerisinde öğrenilir. Hatta öyle ki, Kant'ın hatırlattığı gibi; "sanatta usta, öğrencisine bir sanat ürününü nasıl yaratacağını yaparak gösterir" (Kula, 2012: 154). Yani ustalar sanat eseri yaratmak için genel geçer kurallar koyup bunları öğretmezler, sanat eseri üretmenin nasıl olduğunu üreterek gösterirler. Felsefede de hal böyledir. Çoğunlukla filozofların nasıl felsefe yaptıkları, onları görerek ya da hiç değilse oluşturdukları metinleri yine bir usta ile takibederek kavranır. "Bilginin deneyimle ilişkisi, bildiğini yaşayandan görerek öğrenme geleneği modern eğitimde görülmemektedir. Bir çırağın en önemli mahareti ve vazifesi gözlemlemektir, dinlemektir. Giderek taklit etmektir, nihayet taklit olmaktan öteye geçmektir. Modern eğitim, gözlemleme, görme ve dinleme imkânlarını kaldırmıştır. Epistemolojik bir hadiseye indirgemiştir eğitimi. Oysa usta-çırak ilişkisinde ontolojik bir boyut vardır. Teknik, mimetik bir şeydir sonuçta. Taklide dayanır. Ustası hangi tekniği kullanıyorsa, onu kullanıp geliştirir çırak. Gelenekler böyle oluşur. Üsluplar böyle belirir"(Dellaloğlu, 2012: 58-59). Bir yandan öykünme, taklidetme ve fakat öte yandan farklılaşma, kendisi olma sürecidir sanatın da felsefenin de ustalık serüveni. Bu serüvende ustanın, hocanın rolünü, yani görünür hâle getirme rolünü, şimdi sanattan beklerken, esasında yine o sanat eserini bir felsefi fikrin görünür yüzü olarak ele alabilecek ustalara duyulan ihtiyacı da yadsımamak gerekir. Sadece, görerek öğrenmenin, müşahhas örnekleri görmenin eğitimde oynadığı rol üzerinden, sanata da böyle bir rol biçilebilir mi sorgulamasını yapmaya çalışıyoruz. Öyle bir felsefe eğitimi olsun ki, hem ustası olsun öğreten, hem de ustanın sanat gibi bir malzemesi bulunsun. Zira bugün, yaratıcı düşünme olmaksızın çağı yakalayamayacağımız aşikârdır. Yaratıcı düşünme üzerinde sanatlı bir 
eğitimin ya da sanat eğitiminin rolü inkâr edilemez. "Sanat eğitiminin başlıca amaçlarından biri; görmeyi, işitmeyi, dokunmayı, tad almayı öğretmektir. Çevreyi hakkıyla algılayıp onu biçimlendirmeye yönelmek için bu gerekli bir koşuldur" ( San, 1985: 17). Esasen böyle bir eğitime, her türlü mesleği yapacak olan insanın yetişmesinde ihtiyaç vardır. Özellikle de felsefe alanında bütün bir varlığın sorgulandığı ve yorumlandığı düşünüldüğünde, böyle bir algılama eğitimi, üstelik de ustadan öğrenildiğinde son derece zenginleştirici görünmektedir.

"Tekniğin, insanlara, insanca yaşam sağlayabildiği bir dönemde, teknikten, her zamandan daha çok korkuluyor. Nasıl bir yarın bekliyor dünyamızı? İnsanın insanı sömüreceği, birbirini yok edeceği bir yarın mı, yoksa yaratıcılığın en yüksek değer olarak tanınacağı, yaratıcı-toplumun gerçekleşeceği bir yarın mı?" (İpşiroğlu, 1978: 21). Yaratıcı bir toplum için, topluma karşı sorumluluk duyan yaratıcı bireyler yetiştirmek, hangi meslekte olursa olsun yaratıcilığa ufuk açan bir eğitimle mümkündür. Özellikle topluma ışı tutması beklenen düşünürlerin, felsefecilerin eğitimi, bu yaratıcılık bakımından yeniden değerlendirilmelidir.

Sanatlı bir felsefe ve felsefeli bir sanat teklif etmek belki haddi aşmak olacaktır ancak sanatı bir felsefe eğitimi ve felsefeli bir sanat eğitimi teklif edilebilir. 


\section{Kaynakça}

Cündioğlu, D. (2013). Sanat ve Felsefe, İstanbul: Kapı Yayınları.

Dellaloğlu, B. (2012). Ahmet Hamdi Tanpınar. İstanbul: Kapı Yayınları.

İpşiroğlu, N. ve İpşiroğlu, M. (1987). Sanatta Devrim. İstanbul: Ada Yayınları.

Kula, O. B. (2012). Kant, Schilller, Heidegger/ Estetik ve Edebiyat, isstanbul: İş Bankası Yayınları.

Mevlâna. (1997). Mesnevî. Tercüme ve Açıklama; Şefik Can, Cilt 1 2, 3-4, 5-6. İstanbul: Ötüken Yayınları.

San, i. (1985). Sanat ve Eğitim, Ankara: Ankara Üniversitesi Eğitim Bilimleri Fakültesi Yayınları. 